\title{
Article \\ Thicker Retinal Nerve Fiber Layer with Age among Schoolchildren: The Hong Kong Children Eye Study
}

\author{
Xiu-Juan Zhang ${ }^{1,2}$, Yi-Han Lau ${ }^{1}$, Yu-Meng Wang ${ }^{1}$, Hei-Nga Chan ${ }^{1}$, Poemen P. Chan ${ }^{1,3}$, Ka-Wai Kam ${ }^{1,4}$, \\ Patrick Ip ${ }^{5}$, Wei Zhang ${ }^{2}$, Alvin L. Young ${ }^{1,4}$, Clement C. Tham 1,3,4,6 $\mathbb{D}$, Chi-Pui Pang ${ }^{1,6}$, Li-Jia Chen ${ }^{1,4,6} \mathbb{D}$ \\ and Jason C. Yam $1,3,4,6,7, *$ (D)
}

check for

updates

Citation: Zhang, X.-J.; Lau, Y.-H.; Wang, Y.-M.; Chan, H.-N.; Chan, P.P.; Kam, K.-W.; Ip, P.; Zhang, W.; Young, A.L.; Tham, C.C.; et al. Thicker Retinal Nerve Fiber Layer with Age among Schoolchildren: The Hong Kong Children Eye Study. Diagnostics 2022, 12, 500. https://doi.org/ $10.3390 /$ diagnostics 12020500

Academic Editor: Ramin Khoramnia

Received: 29 January 2022 Accepted: 7 February 2022 Published: 15 February 2022

Publisher's Note: MDPI stays neutral with regard to jurisdictional claims in published maps and institutional affiliations.

Copyright: (c) 2022 by the authors Licensee MDPI, Basel, Switzerland. This article is an open access article distributed under the terms and conditions of the Creative Commons Attribution (CC BY) license (https:// creativecommons.org/licenses/by/ $4.0 /)$.
1 Department of Ophthalmology and Visual Sciences, The Chinese University of Hong Kong, Hong Kong SAR, China; zhangxiujuan@cuhk.edu.hk (X.-J.Z.); glorialau90@gmail.com (Y.-H.L.); ymwang917@gmail.com (Y.-M.W.); hnrubychan@cuhk.edu.hk (H.-N.C.); poemenchan@cuhk.edu.hk (P.P.C.); kamkawai.aziz@gmail.com (K.-W.K.); youngla@ha.org.hk (A.L.Y.); clemtham@cuhk.edu.hk (C.C.T.); cppang@cuhk.edu.hk (C.-P.P.); lijia_chen@cuhk.edu.hk (L.-J.C.)

2 Division of Pediatric Ophthalmology and Strabismus, Tianjin Eye Hospital, Tianjin 300020, China; zhangwei3067@163.com

3 Hong Kong Eye Hospital, Kowloon, Hong Kong SAR, China

4 Department of Ophthalmology and Visual Sciences, Prince of Wales Hospital, Hong Kong SAR, China

5 Department of Paediatrics and Adolescent Medicine, LKS Faculty of Medicine, The University of Hong Kong, Hong Kong SAR, China; patrickiphk@gmail.com

6 Hong Kong Hub of Paediatric Excellence, The Chinese University of Hong Kong, Hong Kong SAR, China

7 Department of Ophthalmology, Hong Kong Children's Hospital, Hong Kong SAR, China

* Correspondence: yamcheuksing@cuhk.edu.hk; Tel.: +852-3943-5892; Fax: +852-2715-9490

\begin{abstract}
This study aims to investigate the effect of age on the peripapillary retinal nerve fiber layer (p-RNFL) thickness among schoolchildren. A total of 4034 children aged 6-8 years old received comprehensive ophthalmological examinations. p-RNFL thickness was measured from a circular scan $(\varnothing=3.4 \mathrm{~mm}$ ) captured using spectral-domain optical coherence tomography (SD-OCT). Associations between $\mathrm{p}$-RNFL thickness with ocular and systemic factors were determined by multivariate linear regression after adjusting potential confounders using generalized estimating equations (GEE). The mean global p-RNFL thickness was $106.60 \pm 9.41 \mu \mathrm{m}$ (range: 72 to $171 \mu \mathrm{m}$ ) in the right eyes, $105.99 \pm 9.30 \mu \mathrm{m}$ (range: 76 to $163 \mu \mathrm{m}$ ) in the left eyes, and 106.29 $\pm 9.36 \mu \mathrm{m}$ (range: 72 to $171 \mu \mathrm{m}$ ) across both eyes. Age was positively correlated with p-RNFL after adjusting for axial length (AL) and confounding factors $(\beta=0.509 ; p=0.001)$. Upon multivariable analysis, AL was positively associated with temporal $p$-RNFL thickness $(\beta=3.186, p<0.001)$ but negatively with non-temporal p-RNFL thickness $(\beta=(10.003,-2.294), p<0.001)$. Sectoral $p$-RNFL was the thickest in the inferior temporal region (155.12 $\pm 19.42 \mu \mathrm{m}$, range 68 to $271 \mu \mathrm{m})$, followed by the superior temporal region $(154.67 \pm 19.99 \mu \mathrm{m}$, range 32 to $177 \mu \mathrm{m})$. To conclude, p-RNFL increased significantly with older age among children 6 to 8 years old in a converse trend compared to adults. Our results provide a reference for interpreting OCT information in children and suggest that stable p-RNFL thickness may not indicate a stable disease status in pediatric patients due to the age effects.
\end{abstract}

Keywords: RNFL thickness; age correlation; children in Hong Kong; OCT measurement

\section{Introduction}

Optic neuropathies in children lead to poor vision and even blindness as a result of conditions including glaucoma, optic nerve hypoplasia, and optic neuritis [1,2]. Early identification, classification, and monitoring of such diseases are crucial for early and effective treatment to preserve eyesight and prevent blindness. Structural investigation of the retinal layers by optical coherence tomography (OCT) is widely used. OCT is a non-contact medical imaging technology using reflected light to produce a detailed crosssectional image of the eye [3,4]. It provides non-invasive, reproducible, high-resolution, 
and in vivo measurements of the retina and retinal nerve fiber layer (RNFL) for adults and children [5]. In particular, RNFL is an ocular structure containing ganglion cell axons, which are important components of the optic nerve. The attenuation of the peripapillary retinal nerve fiber layer ( $\mathrm{p}-\mathrm{RNFL}$ ) is an early sign of loss of optic nerve tissue, which can be effectively detected by OCT.

While OCT investigations have been applied to children for the detection of eye diseases, a normative RNFL thickness database for children still needs to be established. As the eyeballs of children are growing, the patterns of change in RNFL with age are a useful reference for the detection of optic neuropathy in children. In adults, RNFL thinning in older age has been consistently reported [6-9]. On the contrary, the relation between RNFL thickness and age among children varies in different reports [10-12]. Several studies have shown that RNFL thickness does not correlate with age in children or young adults (age between 2 and 21 years) [12-14]. However, a recent study found that RNFL thickness increased with age in children aged $<15$ years old after adjusting for the ocular magnification effect [10]. The influence of age on RNFL thickness in children remains inconclusive. In addition, a significant difference in RNFL thickness among 6-year-old children of different ethnic groups has been reported [15]. We herein conducted a population-based study to evaluate p-RNFL thickness in children aged 6-8 years, in addition to its associations with age and other systemic and ocular factors.

\section{Methods}

\subsection{Study Design and Population}

The Hong Kong Children Eye Study (HKCES) is a population-based cross-sectional study targeting primary school children aged 6-8 years in Hong Kong, who were invited to visit the Chinese University of Hong Kong Eye Centre for comprehensive ophthalmological examinations and investigations. HKCES aims to evaluate various eye conditions among children in this age group and to determine the prevalence and risk factors of different eye diseases. Sample selection for the study was based on a stratified and clustered randomized sampling framework. We first stratified all primary schools registered with the Hong Kong Education Bureau according to the seven hospital clusters used by the Hospital Authority to organize services. After determining the target sample size, 5000 children were then invited to take part in this study, of which 4305 children participated. During the study period, 4273 children completed ophthalmological examinations, including cycloplegic refraction and visual acuity (VA) examinations. Sample size calculations and protocols for the HKCES have been previously reported [16]. The project adhered to the tenets of the Declaration of Helsinki, and approval was obtained from the Ethics Committee Board of the Chinese University of Hong Kong. Participating children and their parents gave informed consent prior to their participation in the study.

\subsection{Ocular and Physical Examinations}

Distance VA was measured using a logarithm of the minimum angle of resolution (logMAR) chart (Nidek Inc., Gamagori, Aichi, Japan). Best-corrected visual acuity (BCVA) was obtained through subjective refraction for all children with a logMAR score greater than 0.1 in either eye, performed by a trained optometrist using a trial frame placed and adjusted on the participants' face. Refractive status was measured both before and after cycloplegia using an auto-refractor (Nidek ARK-510A, Gamagori, Japan) for each child. Two cycles of 1\% cyclopentolate (Cyclogyl, Alcon-Convreur, Rijksweg, Belgium) and 1\% tropicamide (Midorin-P, Santen, Osaka, Japan) were given $10 \mathrm{~min}$ apart. A third cycle of cyclopentolate and tropicamide drops was administered $30 \mathrm{~min}$ later if a pupillary light reflex was still present or the pupil size was less than $6.0 \mathrm{~mm}$. An ophthalmologist would then examine in detail the anterior and posterior segments of each child using a slit-lamp (Haag-Streit, Koeniz, Switzerland) and binocular ophthalmoscope (Volk Optical Inc., Mentor, OH, USA). Spherical equivalent refraction (SER) was defined as spherical diopters (D) plus one-half 
the value for cylindrical diopters. Myopia was defined as SER $\leq-0.50 \mathrm{D}$, emmetropia as $-0.50 \mathrm{D}<\mathrm{SER}<+0.50 \mathrm{D}$, and hyperopia as SER $\geq+0.50 \mathrm{D}$.

Ocular biometry, including axial length (AL) and corneal curvature measurements, was measured through non-contact partial-coherence laser interferometry (IOL Master; Carl Zeiss Meditec, Oberkochen, Germany). AL was measured as the distance from the anterior corneal vertex to the retinal pigment epithelium along fixation, automatically adjusted for retinal thickness. Central corneal thickness and intraocular pressure (IOP) were both measured using a Corvis ST tonometer (OCULUS Optikgeräte GmbH, Wetzlar, Germany). Blood pressure (BP) was measured using an automatic digital blood pressure monitor (Spacelabs Medical, Washington, DC, USA). Height and weight were measured using a professional integrated set (Seca, Hamburg, Germany). Body mass index (BMI) was calculated as body weight (in kilograms) divided by the square of body height (in metres).

\subsection{OCT Imaging}

OCT imaging was performed with a Spectralis SD-OCT (Heidelberg Engineering, Heidelberg, Germany) by a well-trained ophthalmic photographer. All the averaged Bscans in this study had a signal quality of at least $15 \mathrm{~dB}$. p-RNFL imaging was performed at a central wavelength of $870 \mathrm{~nm}$ (Figure 1). The scan circle, with a diameter of approximately $3.45 \mathrm{~mm}$ (1536 A-scans), was manually positioned to locate the optic disc at the center of the circle, with the eye tracking system being activated. Fifteen B-scans were captured at the same location and were averaged automatically by the built-in software (Heidelberg Eye Explorer, version 1.6.1.0; Heidelberg Engineering, Heidelberg, Germany) to increase the image signal-to-noise ratio. The software also automatically segmented the p-RNFL for each averaged B-scan. The mean circumpapillary p-RNFL thickness and sectorial p-RNFL thickness were determined for six sectors: the nasal, temporal, superior nasal, inferior nasal, superior temporal, and inferior temporal regions.

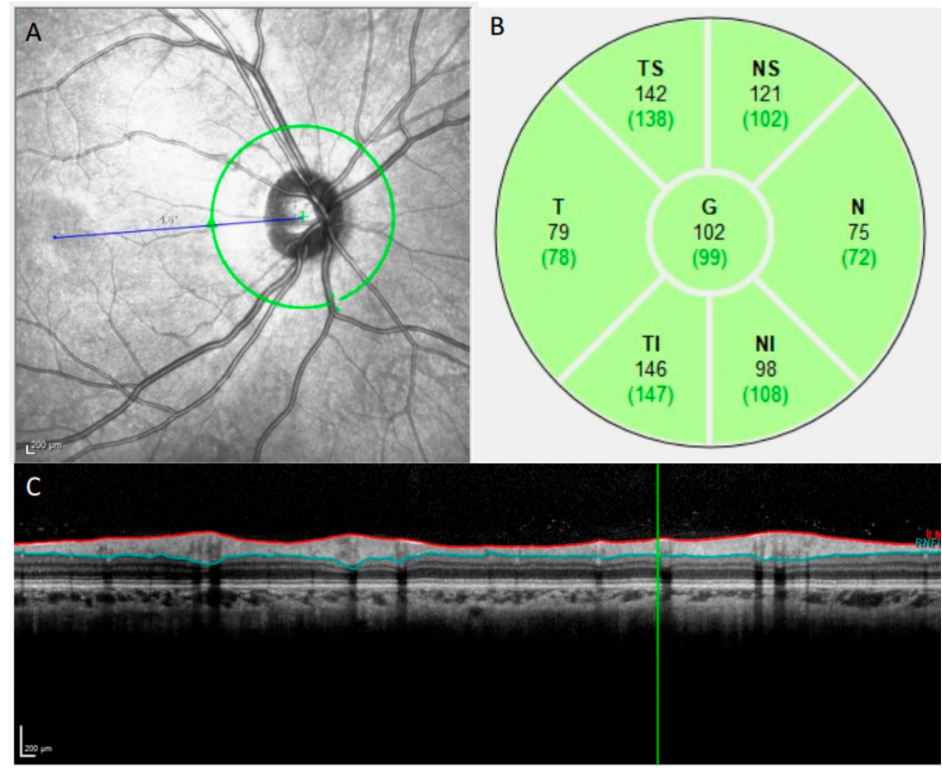

Figure 1. Report sample of the measurement of the retinal nerve fiber layer (RNFL) thickness with OCT. (A) A circle is drawn around the optic disc to measure the peripapillary RNFL thickness. (B) A picture demonstrating the RNFL. (C) Seven measurements were performed for each eye, providing the RNFL thickness of the nasal superior (NS), nasal (N), nasal-inferior (NI), temporal inferior (TI), temporal (T), temporal superior (TS), and global (G) sectors.

\subsection{Statistical Analysis}

SPSS Statistics (version 24.0; IBM Corp., Armonk, NY, USA) was used for all statistical analyses. Confidence intervals (CIs) and $p$ values (significant at a level of $<0.05$ ) were 
derived for the difference estimates, and regression models were applied with adjustments for cluster effects associated with the sampling design. In terms of descriptive statistics, numbers and percentages were reported for the categorical variables, whereas means and standard deviations (SDs) were reported for continuous variables, in addition to the 1st, 5th, 95th, and 99th percentiles. A Gaussian model was assumed for defining the 1st, 5th, and 95th percentile cutoff values for the mean global and sectoral p-RNFL thickness. To determine the associations of p-RNFL thickness with age, ocular, and systemic factors, linear regression models were applied using generalized estimating equations (GEE), with a view to account for inter-eye correlations within individuals in the multivariable analysis.

\section{Results}

\subsection{Study Population}

Among the 4273 children recruited, 159 children declined or could not complete the OCT examination. Another 80 children were excluded due to suboptimal imaging quality. Consequently, 8068 eyes from 4034 children were included in the final analysis, including 2067 boys (51.2\%) and 1967 girls (48.8\%), with a mean age of $7.61 \pm 0.98$ years (Table 1$)$.

Table 1. Baseline characteristics of the school children in this study.

\begin{tabular}{|c|c|}
\hline \multicolumn{2}{|c|}{ Sex } \\
\hline Male, N (\%) & $2067(51.2 \%)$ \\
\hline Female, N (\%) & $1967(48.8 \%)$ \\
\hline Age $($ mean $\pm S D)$, years & $7.61 \pm 0.98$ \\
\hline Body mass index (mean $\pm S D), \mathrm{kg} / \mathrm{m}^{2}$ & $16.14 \pm 2.88$ \\
\hline Systolic blood pressure (mean $\pm \mathrm{SD}), \mathrm{mm} \mathrm{Hg}$ & $101.51 \pm 11.13$ \\
\hline Diastolic blood pressure (mean $\pm \mathrm{SD}$ ), $\mathrm{mm} \mathrm{Hg}$ & $64.50 \pm 9.03$ \\
\hline \multicolumn{2}{|l|}{ Visual acuity, logMAR unit } \\
\hline Right eyes (Mean \pm SD) & $0.01 \pm 0.05$ \\
\hline Left eyes (Mean \pm SD) & $0.02 \pm 0.05$ \\
\hline \multicolumn{2}{|l|}{ Axial length (mm) } \\
\hline Right eyes (Mean \pm SD) & $23.14 \pm 0.94$ \\
\hline Left eyes (Mean \pm SD) & $23.13 \pm 0.94$ \\
\hline \multicolumn{2}{|l|}{ Spherical equivalent, D } \\
\hline Right eyes (Mean \pm SD) & $0.13 \pm 1.56$ \\
\hline Left eyes (Mean \pm SD) & $0.17 \pm 1.57$ \\
\hline \multicolumn{2}{|l|}{ Central corneal thickness, $\mu \mathrm{m}$} \\
\hline Right eyes (Mean \pm SD) & $549.50 \pm 32.51$ \\
\hline Left eyes (Mean \pm SD) & $551.27 \pm 31.83$ \\
\hline \multicolumn{2}{|l|}{ Intraocular Pressure, $\mathrm{mmHg}$} \\
\hline Right eyes (Mean \pm SD) & $15.57 \pm 2.53$ \\
\hline Left eyes (Mean \pm SD) & $15.86 \pm 2.77$ \\
\hline $\log \mathrm{MAR}$, logarithm of the minimum angle of resolution & \\
\hline
\end{tabular}

\subsection{Normal Ranges of Global and Sectoral p-RNFL Thickness}

The means for global p-RNFL thickness in the right and left eyes were $106.60 \pm 9.41 \mu \mathrm{m}$ (range: 72 to $171 \mu \mathrm{m}$ ) and $105.99 \pm 9.30 \mu \mathrm{m}$ (range: 76 to $163 \mu \mathrm{m}$ ), respectively. The mean was $106.29 \pm 9.36 \mu \mathrm{m}$ (range: 72 to $171 \mu \mathrm{m}$ ) for both eyes. Regarding the sectors in both eyes, the temporal inferior sector had the thickest mean p-RNFL (155.12 $\pm 19.42 \mu \mathrm{m}$, range 68 to $271 \mu \mathrm{m})$, while the nasal sector had the thinnest mean p-RNFL $(66.11 \pm 14.12 \mu \mathrm{m}$, range 32 to $177 \mu \mathrm{m}$; Table 2). 
Table 2. Ranges of peripapillary retinal nerve fiber layer thickness in global and different sectors.

\begin{tabular}{|c|c|c|c|c|c|c|c|c|c|c|c|c|c|c|c|c|c|c|}
\hline \multirow{3}{*}{$\begin{array}{l}\text { p-RNFL } \\
\text { Thickness, } \mu \mathrm{m}\end{array}$} & \multicolumn{6}{|c|}{ Right Eyes } & \multicolumn{6}{|c|}{ Left Eyes } & \multicolumn{6}{|c|}{ Both Eyes } \\
\hline & \multirow[b]{2}{*}{$\begin{array}{l}\text { Mean } \\
\text { (SD) }\end{array}$} & \multirow[b]{2}{*}{ Range } & \multicolumn{4}{|c|}{ Percentiles } & \multicolumn{8}{|c|}{ Percentiles } & \multicolumn{4}{|c|}{ Percentiles } \\
\hline & & & 1 st & 5 th & 95th & 99th & $\begin{array}{l}\text { Mean } \\
\text { (SD) }\end{array}$ & Range & $1 s t$ & 5 th & 95th & 99th & $\begin{array}{l}\text { Mean } \\
\text { (SD) }\end{array}$ & Range & 1st & 5 th & 95th & 99th \\
\hline Global & $\begin{array}{l}106.60 \\
(9.41)\end{array}$ & (72 to 171 ) & 85.34 & 92.00 & 122.00 & 131.25 & $\begin{array}{l}105.99 \\
(9.30)\end{array}$ & (76 to 163 ) & 84.84 & 91.50 & 121.50 & 130.16 & $\begin{array}{l}106.29 \\
(9.36)\end{array}$ & (72 to 171 ) & 85.25 & 91.75 & 121.75 & 131.00 \\
\hline $\begin{array}{l}\text { Temporal } \\
\text { superior }\end{array}$ & $\begin{array}{l}154.22 \\
(20.53)\end{array}$ & (65 to 269 ) & 103.00 & 122.00 & 188.00 & 207.00 & $\begin{array}{l}155.12 \\
(19.42)\end{array}$ & (61 to 258 ) & 111.00 & 124.00 & 187.00 & 206.65 & $\begin{array}{l}154.67 \\
(19.99)\end{array}$ & (61 to 269 ) & 106.00 & 123.00 & 187.55 & 207.00 \\
\hline Temporal & $\begin{array}{c}83.98 \\
(13.13)\end{array}$ & (51 to 214) & 60.00 & 66.00 & 106.00 & 123.00 & $\begin{array}{c}81.99 \\
(12.40)\end{array}$ & (41 to 198 ) & 58.00 & 64.00 & 104.00 & 118.65 & $\begin{array}{c}82.99 \\
(12.81\end{array}$ & (41 to 214 ) & 59.00 & 65.00 & 105.00 & 121.00 \\
\hline $\begin{array}{l}\text { Temporal } \\
\text { inferior }\end{array}$ & $\begin{array}{l}155.65 \\
(19.11)\end{array}$ & (88 to 271 ) & 114.00 & 127.00 & 188.00 & 204.65 & $\begin{array}{l}154.60 \\
(19.72)\end{array}$ & (68 to 235 ) & 106.35 & 124.00 & 187.00 & 201.00 & $\begin{array}{l}155.12 \\
(19.42)\end{array}$ & (68 to 271 ) & 111.00 & 125.00 & 188.00 & 203.31 \\
\hline Nasal inferior & $\begin{array}{l}117.26 \\
(23.69)\end{array}$ & (46 to 231 ) & 68.00 & 80.75 & 156.00 & 181.65 & $\begin{array}{l}115.83 \\
(23.45)\end{array}$ & (38 to 247 ) & 67.00 & 80.00 & 156.00 & 175.65 & $\begin{array}{l}116.51 \\
(23.47)\end{array}$ & (38 to 247 ) & 67.00 & 80.00 & 156.00 & 178.00 \\
\hline Nasal & $\begin{array}{c}68.34 \\
(14.15)\end{array}$ & (32 to 199) & 40.00 & 48.00 & 92.00 & 107.65 & $\begin{array}{c}63.88 \\
(13.73)\end{array}$ & (32 to 177 ) & 39.00 & 45.00 & 87.00 & 101.00 & $\begin{array}{c}66.11 \\
(14.12)\end{array}$ & (32 to 177 ) & 39.69 & 46.00 & 90.00 & 104.00 \\
\hline Nasal superior & $\begin{array}{l}121.14 \\
(20.75)\end{array}$ & (45 to 212 ) & 76.00 & 89.00 & 156.00 & 177.00 & $\begin{array}{l}130.46 \\
(22.45)\end{array}$ & (41 to 234 ) & 80.35 & 96.00 & 168.00 & 190.00 & $\begin{array}{l}125.77 \\
(22.01)\end{array}$ & (41 to 234 ) & 78.00 & 92.00 & 163.00 & 187.00 \\
\hline
\end{tabular}




\subsection{Associations of Global and Sectoral p-RNFL Thickness with Age}

After adjusting for confounders, including age, gender, AL, BMI, systolic and diastolic $\mathrm{BP}$, central corneal thickness, and IOP, an older age was associated with a thicker global p-RNFL $(\beta=0.509 ; 95 \% C I=(0.21,0.80) ; p=0.001$; Table 3$)$. This association with age was significant for $p$-RNFL thickness in the superior temporal $(\beta=0.953 ; 95 \% C I=(0.35,1.56)$; $p=0.002)$, inferior temporal $(\beta=1.372 ; 95 \% \mathrm{CI}=(0.76,1.99) ; p<0.001)$, superior nasal $(\beta=0.955 ; 95 \% C I=(0.29,1.62) ; p=0.005)$ and inferior nasal $(\beta=0.772 ; 95 \% C I=(0.06$, $1.48) ; p=0.03$ ) regions (Table 4$)$. Stratified by age, the mean global $p-R N F L$ thickness was deceased by 6-, 7-, and 8-year age groups in myopia $(p=0.001)$, emmetropia $(p=0.028)$, and hyperopia $(p=0.023)$, respectively (Supplementary Materials Table S1).

Table 3. Association of ocular and systemic factors with global peripapillary retinal nerve fiber layer thickness.

\begin{tabular}{lcccc}
\hline Parameters & $\boldsymbol{\beta}$ & \multicolumn{2}{c}{$\mathbf{9 5 \%}$ CI } & $p$ Values \\
\hline Age & 0.509 & 0.21 & 0.80 & 0.001 \\
Sex & 1.013 & 0.42 & 1.60 & 0.001 \\
Body mass index, $\mathrm{kg} / \mathrm{m}^{2}$ & 0.140 & 0.03 & 0.25 & 0.013 \\
Systolic blood pressure, $\mathrm{mm} \mathrm{Hg}$ & -0.011 & -0.05 & 0.02 & 0.547 \\
Diastolic blood pressure, $\mathrm{mm} \mathrm{Hg}$ & -0.001 & -0.04 & 0.04 & 0.946 \\
Axial length, mm & -2.917 & -3.23 & -2.61 & $<0.001$ \\
Intraocular Pressure, $\mathrm{mmHg}$ & -0.115 & -0.18 & -0.06 & $<0.001$ \\
CCT, $\mu \mathrm{m}$ & 0.000 & -0.01 & 0.01 & 0.898 \\
\hline
\end{tabular}

$\beta$ was adjusted for all the ocular and systemic factors in the table. ${ }^{*}$ : male $=1$, female $=2$.

Table 4. Association of ocular and systemic factors with sectional peripapillary retinal nerve fiber layer thickness.

\begin{tabular}{|c|c|c|c|c|c|c|c|c|c|c|c|c|}
\hline \multirow{3}{*}{$\begin{array}{l}\text { Parameters } \\
\text { Age }\end{array}$} & \multirow{3}{*}{$\frac{\beta}{0.953}$} & \multicolumn{3}{|c|}{ Temporal Superior } & \multirow{3}{*}{$\frac{\beta}{-0.210}$} & \multirow{2}{*}{\multicolumn{2}{|c|}{$\begin{array}{c}\text { Temporal } \\
95 \% \text { CI }\end{array}$}} & \multirow{3}{*}{$\frac{p \text { Values }}{0.305}$} & \multirow{3}{*}{$\frac{\boldsymbol{\beta}}{1.372}$} & \multicolumn{2}{|c|}{ Temporal Inferior } & \multirow{3}{*}{$\frac{p \text { Values }}{0.000}$} \\
\hline & & 95 & & $p$ Values & & & & & & & & \\
\hline & & 0.35 & 1.56 & 0.002 & & -0.61 & 0.19 & & & 0.76 & 1.99 & \\
\hline Sex* & 1.568 & 0.36 & 2.77 & 0.011 & -2.637 & -3.42 & -1.85 & 0.000 & -0.982 & -2.19 & 0.22 & 0.110 \\
\hline Body mass index, $\mathrm{kg} / \mathrm{m}^{2}$ & 0.133 & -0.08 & 0.35 & 0.223 & 0.093 & -0.05 & 0.23 & 0.195 & 0.190 & -0.02 & 0.40 & 0.081 \\
\hline $\begin{array}{l}\text { Systolic blood pressure, } \\
\mathrm{mm} \mathrm{Hg}\end{array}$ & -0.053 & -0.12 & 0.02 & 0.134 & -0.005 & -0.05 & 0.04 & 0.822 & -0.011 & -0.08 & 0.06 & 0.765 \\
\hline $\begin{array}{l}\text { Diastolic blood pressure, } \\
\mathrm{mm} \mathrm{Hg}\end{array}$ & 0.058 & -0.02 & 0.14 & 0.163 & 0.009 & -0.04 & 0.06 & 0.745 & -0.013 & -0.10 & 0.07 & 0.761 \\
\hline Axial length, $\mathrm{mm}$ & -2.294 & -2.96 & -1.63 & 0.000 & 3.186 & 2.75 & 3.62 & 0.000 & -2.682 & -3.36 & -2.00 & 0.000 \\
\hline $\begin{array}{l}\text { Intraocular Pressure, } \\
\mathrm{mmHg}\end{array}$ & -0.228 & -0.40 & -0.05 & 0.011 & -0.069 & -0.18 & 0.04 & 0.229 & -0.208 & -0.38 & -0.03 & 0.019 \\
\hline $\mathrm{CCT}, \mu \mathrm{m}$ & -0.004 & -0.02 & 0.01 & 0.667 & -0.002 & -0.01 & 0.01 & 0.707 & 0.000 & -0.02 & 0.02 & 0.970 \\
\hline Age & 0.772 & 0.06 & 1.48 & 0.034 & 0.175 & -0.25 & 0.60 & 0.425 & 0.955 & 0.29 & 1.62 & 0.005 \\
\hline Sex* & 3.633 & 2.24 & 5.02 & 0.000 & 2.375 & 1.54 & 3.21 & 0.000 & 4.486 & 3.17 & 5.80 & 0.000 \\
\hline Body mass index, $\mathrm{kg} / \mathrm{m}^{2}$ & 0.214 & -0.03 & 0.46 & 0.083 & 0.137 & -0.01 & 0.28 & 0.060 & 0.123 & -0.11 & 0.36 & 0.309 \\
\hline $\begin{array}{l}\text { Systolic blood pressure, } \\
\mathrm{mm} \mathrm{Hg}\end{array}$ & -0.015 & -0.09 & 0.06 & 0.704 & 0.016 & -0.03 & 0.06 & 0.535 & -0.021 & -0.09 & 0.05 & 0.568 \\
\hline $\begin{array}{l}\text { Diastolic blood pressure, } \\
\mathrm{mm} \mathrm{Hg}\end{array}$ & -0.003 & -0.09 & 0.09 & 0.957 & -0.027 & -0.08 & 0.03 & 0.331 & -0.014 & -0.10 & 0.07 & 0.746 \\
\hline Axial length, mm & -10.003 & -10.77 & -9.23 & 0.000 & -4.071 & -4.53 & -3.61 & 0.000 & -6.305 & -7.04 & -5.57 & 0.000 \\
\hline $\begin{array}{l}\text { Intraocular Pressure, } \\
\mathrm{mmHg}\end{array}$ & -0.275 & -0.47 & -0.08 & 0.005 & -0.192 & -0.32 & -0.07 & 0.003 & 0.024 & -0.17 & 0.22 & 0.807 \\
\hline $\mathrm{CCT}, \mu \mathrm{m}$ & 0.000 & -0.02 & 0.02 & 0.989 & -0.004 & -0.02 & 0.01 & 0.496 & 0.008 & -0.01 & 0.03 & 0.391 \\
\hline
\end{tabular}

$\beta$ was adjusted for all the ocular and systemic factors in the table. ${ }^{*}$ : male $=1$, female $=2$.

\subsection{Associations of Global and Sectoral p-RNFL Thickness with Other Factors}

Global p-RNFL thickness was negatively associated with AL $(\beta=-2.917 ; 95 \% \mathrm{CI}=$ $(-3.23,-2.61) ; p<0.001)$ and IOP $(\beta=-0.115 ; 95 \% \mathrm{CI}=(-0.18,-0.05) ; p<0.001)$ (Table 3$)$. BMI and female sex had a positive association with global $p$-RNFL thickness $(\beta=0.140$; $95 \% \mathrm{CI}=(0.03,0.25) ; p=0.013 ; \beta=1.013 ; 95 \% \mathrm{CI}=(0.42,1.60), p=0.001)$ (Table 3$)$. AL was negatively associated with the sector $\mathrm{p}$-RNFL thicknesses in all non-temporal quadrants $(\beta=(-10.003,-2.294) ; p<0.001)$, but positively associated with thickness in the temporal quadrant $(\beta=3.186 ; p<0.001)$. Intraocular pressure was negatively associated with sectoral 
p-RNFL thicknesses for the temporal superior, temporal inferior, nasal superior, and nasal inferior regions $(\beta=(-0.275,-0.192) ; p<0.05)$ (Table 4$)$.

\section{Discussion}

In this population-based study of healthy Chinese schoolchildren aged 6-8 years, we established a normative database of p-RNFL thickness. Notably, p-RNFL was thicker with age in children from 6 to 8 years old, a converse trend as that seen for adults [7]. Moreover, as AL increased, global p-RNFL thickness decreased, whereas temporal p-RNFL thickness increased. These findings indicate a different phenotype for $\mathrm{p}$-RNFL in children as compared to adults. Furthermore, for pediatric patients with optic neuropathies, stable p-RNFL thickness may not indicate a stable disease status because of age in children.

\subsection{Comparison of Age Correlation in Other Studies}

Whereas the impact of age on RNFL thickness in adults has been widely regarded to be a negative correlation $[17,18]$, its influence on RNFL thickness in children remains inconclusive. The studies by Yanni et al. [19] and Salchow et al. [20] reported similar decreases in RNFL thickness due to ageing among individuals in the age ranges of 5-15 years and 5-17 years, respectively. Nevertheless, most studies among different populations, including Mongolian, Hispanic, African-American, and Asian groups, found that RNFL thickness did not correlate with age in children or young adults aged between 2 to 21 years old (Table 5) [12-14,21]. A recent meta-analysis also concluded that the majority of reported studies showed no association between age and OCT parameters [22]. In the current study, we found that age was positively correlated with global p-RNFL thickness $(p=0.001)$. Our results are consistent with the positive correlation between ocular magnification-corrected average RNFL thickness and age in a study of 198 children under 15 years of age [10]. The variations between different studies may partly explained by different age rages, ethnics, and OCT measurements. The covariates that can be significantly associated with p-RNFL thickness should be adjusted. Hong and colleagues found that RNFL thickness measurements in children are likely to be overestimated if ocular magnification effects are not corrected [10]. In the current study, we adjusted known covariates such as Al, BMI, and IOP to ensure the accuracy of the results.

Table 5. Summary of studies on global peripapillary retinal nerve fiber layer thickness and correlation with age in children.

\begin{tabular}{|c|c|c|c|c|c|}
\hline Study & Ethnicity & $\begin{array}{c}\text { Age, Years } \\
\text { (Mean } \pm \text { SD; Range) }\end{array}$ & Type of OCT & $\begin{array}{l}\text { Mean Global RNFL } \\
\text { Thickness }(\mu \mathrm{m})\end{array}$ & $\begin{array}{l}\text { Correlation } \\
\text { with Age }\end{array}$ \\
\hline Present study & Chinese $(n=4034)$ & $7.61 \pm 0.98 ; 6-8$ & SD-OCT & $106.29 \pm 9.36$ & $\begin{array}{l}\text { Positively } \\
\text { correlated }\end{array}$ \\
\hline Wang CY, et al. (2018) [12] & $\begin{array}{l}\text { Chinese and Mongolian } \\
\qquad(\mathrm{n}=1565)\end{array}$ & $11.9 \pm 3.5 ; 6-21$ & SD-OCT & $101.3 \pm 9.2$ & No correlation \\
\hline Hong SW, et al. (2017) [10] & Korean $(n=198)$ & $8.61 \pm 3.12 ; 2-18$ & Stratus OCT & $107.71 \pm 11.83$ & $\begin{array}{l}\text { Positively } \\
\text { correlated }\end{array}$ \\
\hline Kang MT, et al. (2016) [13] & Chinese $(n=2893)$ & $7.1 \pm 0.4 ; 5.7-9.1$ & SD OCT & $102.01 \pm 8.02$ & Not reported \\
\hline Chen L, et al. (2013) [23] & Chinese $(\mathrm{n}=2324)$ & $12.82 \pm 3.11 ; 6-17$ & OCT-iVue100 & $106.89 \pm 12.84$ & No correlation \\
\hline Yanni SE, et al. (2013) [21] & $\begin{array}{c}\text { non-Hispanic, African } \\
\text { American, Hispanic, and } \\
\text { Asian }(\mathrm{n}=83)\end{array}$ & $9.14 ; 5-15$ & SD OCT & $107.6 \pm 1.2$ & $\begin{array}{l}\text { Negatively } \\
\text { correlated }\end{array}$ \\
\hline Zhu BD, et al. (2013) [22] & Chinese $(n=2105)$ & $12.34 \pm 0.58 ; 10-16$ & SD-OCT & $103.08 \pm 9.01$ & No correlation \\
\hline Tsai DC, et al. (2011) & $\begin{array}{l}\text { Taiwanese }(\mathrm{n}=470) \\
\text { Caucasian, African }\end{array}$ & $7-12$ & SD-OCT & $109.4 \pm 10.0$ & No correlation \\
\hline Huynh SC, et al. (2006) & $\begin{array}{c}\text { American, Asian, and } \\
\text { Hispanic }(\mathrm{n}=1369)\end{array}$ & $6.71 \pm 0.4$ & Stratus OCT & $103.7 \pm 11.4$ & No correlation \\
\hline $\begin{array}{l}\text { Salchow DJ, et al. (2005) } \\
\text { [22] }\end{array}$ & $\begin{array}{l}\text { Hispanic, African American, } \\
\text { Caucasian }(\mathrm{n}=92)\end{array}$ & $9.7 \pm 2.7 ; 4-17$ & Stratus OCT & $107.0 \pm 11.1$ & $\begin{array}{l}\text { Negatively } \\
\text { correlated }\end{array}$ \\
\hline Neelam, P, et al. (2014) & Indian $(\mathrm{n}=120)$ & $\begin{array}{l}10.8 \pm 3.24 \text { years } \\
\quad(\text { range } 5-17)\end{array}$ & Stratus OCT & $106.11 \pm 9.5$ & No correlation \\
\hline Leung, et al. (2010) & Chinese $(\mathrm{n}=104)$ & $9.75 ;(6.08-17.58)$ & Optical OCT & 113 & No correlation \\
\hline Al-haddad Christiane & Middle Eastern $(\mathrm{n}=108)$ & $10.7 \pm 3.1$ & Cirrus OCT & $95.6 \pm 8.7$ & No correlation \\
\hline
\end{tabular}

SD OCT: Spectral domain optical coherence tomography.

Among all sectors, we found that the superior and inferior sectoral p-RNFL parameters are, in particular, increased with age. These sectoral variations may be due to the larger 
numbers of nerve fibers converging to the optic nerve head from the superior and inferior arcuate bundles, relative to the numbers converging from the papillomacular bundle and nasal retina.

We propose that the increases in superior and inferior p-RNFL thickness among children could be attributed to an increase in axon diameter, glial cell proliferation, and/or formation of the radial peripapillary capillary network [10]. In pediatric patients, RNFL damage could be concealed by an increase in p-RNFL thickness with age. A stable p-RNFL thickness may therefore not necessarily indicate a stable disease status in pediatric patients with conditions such as pediatric glaucoma.

\subsection{Comparison of Mean p-RNFL Thickness with Other Studies}

The mean global p-RNFL thickness $(106.29 \pm 9.36 \mu \mathrm{m})$ for the schoolchildren in our study population was comparable to measurements obtained on healthy North American children aged $5-15$ years $(107.6 \pm 1.2 \mu \mathrm{m})$ [19]. Similar results were also found among Asian children [10,12,23,24]. The mean global RNFL thickness was $107.71 \pm 11.83 \mu \mathrm{m}$ among Korean children aged 2-17 years [10] and $106.89 \pm 12.84 \mu \mathrm{m}$ among Shanghai Chinese students aged 6-11 years [23]. The published reports summarized in Table 5 indicate consistent mean global p-RNFL thickness in our and other studies.

\subsection{Other Factors with Significant Correlations with $p$-RNFL}

The significant correlation between p-RNFL thickness and AL in this study is consistent with previous reports $[18,25]$. The RNFL thinning related to a longer AL may be due to axial elongation in the posterior segment resulting from mechanical stretching by eyeball elongation [12]. In the current study, AL was correlated negatively with sectoral p-RNFL thickness in all non-temporal quadrants, but correlated positively with the temporal quadrant. This is consistent with previous studies among both adults and children $[13,26]$. There is likely a redistribution of retinal nerve fiber with increasing AL in myopia, in which the retinal thickness in the most central area-the temporal sector of the RNFL-is preserved, but the peripheral retina becomes thinner as it is less resistant to traction and stretch [23]. As the axial length increases, the retina is dragged towards the temporal horizon, and consequently the RNFL thickens in the temporal quadrant [27].

The topographic distribution pattern of RNFL thickness (temporal inferior $>$ temporal superior $>$ nasal inferior $>$ nasal superior $>$ temporal $>$ nasal) found in this study has been consistently reported among normal children and adults [8,12]. The regional distribution of RNFL thickness corresponds with regional differences in the mean thickness of retinal ganglion cell axons in the retrobulbar part of the optic nerve, with thicker axons located in the inferior and superior regions, and the thinnest axons located in the temporal region [28]. The uneven sectoral distribution in RNFL thickness may be related to retinal anatomy, with the fovea being located about $0.5 \mathrm{~mm}$ inferior to a horizontal line drawn through the center of the optic disc [28]. This uneven distribution may lead to more retinal surface area and more retinal cells in the region inferior to the horizontal optic disc axis compared with the region superior to the axis.

Elevated IOP remains a major risk factor of glaucoma. IOP was significantly associated with rates of progressive RNFL loss in glaucoma patients [29]. However, the association of IOP with RNFL thickness in healthy adults and children is not clear. In this study, elevated IOP was related to thinner $\mathrm{p}$-RNFL thickness in children. The true effect of IOP on p-RNFL thickness in a healthy population remains unknown. In a monkey model, there was a dynamic association between the high levels of IOP and RNFL thickness loss without drug intervention [30]. Future studies are needed to explore this relationship. Our results indicated that adjustments for IOP are necessary when making comparisons regarding p-RNFL thickness. Our study also found that global p-RNFL thickness in children did not decrease with higher blood pressure, but was positively related to a higher BMI. This finding is in contrast with studies on adults, in which the prevalence of localized RNFL defects was higher and the overall RNFL thickness was reduced among individuals with arterial 
hypertension and obesity [31-33]. One study showed a negative correlation between blood pressure (BP) and the mean global RNFL thickness, which suggested that good BP control among hypertensive subjects would help RNFL preservation [34]. A possible explanation for the discrepancy is that the damage of hypertension or obesity on arterioles of the retina and optic nerve head may be a long-term process. Lastly, girls have a greater myopic tendency and steeper corneal curvatures (i.e., shorter corneal radius of curvature) than boys [35]. The global RNFL thickness among females was $1 \mu \mathrm{m}$ thicker than in males aged 40 to 80 years [36]. Estrogen production among females would lead to a protective effect on RNFL through estrogen receptors on RGCs [36]. This may partly explain the thicker p-RNFL observed for girls in our study population.

\subsection{Strengths and Limitations}

The strength of this study includes its large-scale population-based setting, in addition to its standardized randomized sampling method, which could eliminate sampling selection bias. Our final sample should be representative of the Chinese children population. Meanwhile, there are several limitations in the study. First, other optic disc parameters, such as disc size, have not been determined. Thus, the association between the size of the optic disc and p-RNFL thickness could not be explored. Second, the target age range of the children was 6-8 years. Our study population includes a narrow age band; hence, the study results may not be applicable to other populations. A large age range would provide more information on the trend of p-RNFL thickness with younger and older ages.

\section{Conclusions}

In conclusion, p-RNFL increases significantly with older age among children 6 to 8 years old. It is a converse trend compared to adults. A stable p-RNFL thickness may not warrant a stable disease status in pediatric patients. There is a different RNFL phenotype with age among children compared to adults. Our results provide a useful reference for interpreting tomography information in children.

Supplementary Materials: The following are available online at https:/ /www.mdpi.com/article/ 10.3390/diagnostics12020500/s1, Table S1: Global RNFL Thickness by Different Age in Myopia, Emmetropia and Hyperopia Groups.

Author Contributions: Writing—original draft, X.-J.Z., Y.-H.L., Y.-M.W. and H.-N.C.; Writingreview \& editing, P.P.C., K.-W.K., P.I., W.Z., A.L.Y., C.C.T., C.-P.P., L.-J.C. and J.C.Y. All authors have read and agreed to the published version of the manuscript.

Funding: This study was supported in part by CUHK Jockey Club Children Eye Care Program; the General Research Fund (GRF), Research Grants Council, Hong Kong (14111515 and 14103419 (JCY)); the Health and Medical Research Fund (HMRF), Hong Kong (5160836 (LJC) and 07180826 (XJZ)); the Direct Grants of the Chinese University of Hong Kong, (4054193 (LJC), and 4054121 and 4054199 (JCY)).

Institutional Review Board Statement: The study was approved by the Ethics Committee Board of the Chinese University of Hong Kong (2015.033, approved in year 2015).

Informed Consent Statement: Informed consent was obtained from all subjects involved in the study. Written informed consent has been obtained from the patient(s) to publish this paper.

Data Availability Statement: The data presented in this study are available in Tables 1-5.

Acknowledgments: We thank all the children and their families for their participation in the Hong Kong Children Eye Study. We also thank our colleagues and volunteers for all their hard work and dedication in data collection for this study. We are very grateful to Mandy P.H. Ng from the Department of Ophthalmology and Visual Sciences, the Chinese University of Hong Kong, for her overall coordination efforts and logistic arrangements for the study.

Conflicts of Interest: The authors declare no conflict of interest. 


\section{References}

1. Chong, C.; McGhee, C.N.J.; Dai, S.H. Causes of childhood low vision and blindness in New Zealand. Clin. Exp. Ophthalmol. 2019, 47, 165-170. [CrossRef]

2. Alshigari, R.; Freidi, A.; Souru, C.; Edward, D.P.; Malik, R. Risk Factors for Blindness in Children with Primary Congenital Glaucoma-Follow-up of a Registry Cohort. Am. J. Ophthalmol. 2021, 224, 238-245. [CrossRef]

3. Methe, B.A.; Nelson, K.E.; Pop, M.; Creasy, H.H.; Giglio, M.G.; Huttenhower, C.; Gevers, D.; Petrosino, J.F.; Abubucker, S.; Badger, J.H.; et al. A framework for human microbiome research. Nature 2012, 486, 215-221.

4. Maccora, K.A.; Sheth, S.; Ruddle, J.B. Optical coherence tomography in paediatric clinical practice. Clin. Exp. Optom. 2019, 102, 300-308. [CrossRef]

5. Avery, R.A.; Rajjoub, R.D.; Trimboli-Heidler, C.; Waldman, A.T. Applications of optical coherence tomography in pediatric clinical neuroscience. Neuropediatrics 2015, 46, 88-97.

6. Hondur, G.; Goktas, E.; Al-Aswad, L.; Tezel, G. Age-related changes in the peripheral retinal nerve fiber layer thickness. Clin. Ophthalmol. 2018, 12, 401-409. [CrossRef]

7. Chen, C.Y.; Huang, E.J.; Kuo, C.N.; Wu, P.L.; Chen, C.L.; Wu, P.C.; Wu, S.H.; King, Y.C.; Lai, C.H. The relationship between age, axial length and retinal nerve fiber layer thickness in the normal elderly population in Taiwan: The Chiayi eye study in Taiwan. PLOS ONE 2018, 13, e0194116. [CrossRef]

8. Wang, Y.X.; Pan, Z.; Zhao, L.; You, Q.S.; Xu, L.; Jonas, J.B. Retinal nerve fiber layer thickness. The Beijing Eye Study 2011. PLoS ONE 2013, 8, e66763. [CrossRef]

9. $\quad$ Sung, K.R.; Wollstein, G.; Bilonick, R.A.; Townsend, K.A.; Ishikawa, H.; Kagemann, L.; Noecker, R.J.; Fujimoto, J.G.; Schuman, J.S. Effects of age on optical coherence tomography measurements of healthy retinal nerve fiber layer, macula, and optic nerve head. Ophthalmology 2009, 116, 1119-1124. [CrossRef]

10. Hong, S.W.; Ahn, Y.J.; Kang, N.Y. Relationship between Age and Retinal Nerve Fiber Layer Thickness in Normal Children. Semin. Ophthalmol. 2017, 32, 655-660. [CrossRef]

11. Al-Haddad, C.; Barikian, A.; Jaroudi, M.; Massoud, V.; Tamim, H.; Noureddin, B. Spectral domain optical coherence tomography in children: Normative data and biometric correlations. BMC Ophthalmol. 2014, 14, 53. [CrossRef]

12. Wang, C.Y.; Zheng, Y.F.; Liu, B.; Meng, Z.W.; Hong, F.; Wang, X.X.; Wang, X.J.; Du, L.; Wang, I.Y.; Zhu, D.; et al. Retinal Nerve Fiber Layer Thickness in Children: The Gobi Desert Children Eye Study. Investig. Ophthalmol. Vis. Sci. 2018, 59, 5285-5291. [CrossRef]

13. Kang, M.T.; Li, S.M.; Li, H.; Li, L.; Li, S.Y.; Zhu, B.D.; Guo, Y.Q.; Meng, B.; Sun, Y.Y.; Ran, A.; et al. Peripapillary retinal nerve fibre layer thickness and its association with refractive error in Chinese children: The Anyang Childhood Eye Study. Clin. Exp. Ophthalmol. 2016, 44, 701-709. [CrossRef]

14. Hong, S.W.; Ahn, M.D.; Kang, S.H.; Im, S.K. Analysis of peripapillary retinal nerve fiber distribution in normal young adults. Investig. Ophthalmol. Vis. Sci. 2010, 51, 3515-3523. [CrossRef]

15. Huynh, S.C.; Wang, X.Y.; Rochtchina, E.; Mitchell, P. Peripapillary retinal nerve fiber layer thickness in a population of 6-year-old children: Findings by optical coherence tomography. Ophthalmology 2006, 113, 1583-1592. [CrossRef]

16. Yam, J.C.; Tang, S.M.; Kam, K.W.; Chen, L.J.; Yu, M.; Law, A.K.; Yip, B.H.; Wang, Y.M.; Cheung, C.Y.L.; Ng, D.S.C.; et al. High prevalence of myopia in children and their parents in Hong Kong Chinese Population: The Hong Kong Children Eye Study. Acta Ophthalmol. 2020, 98, e639-e648. [CrossRef]

17. Zhao, L.; Wang, Y.; Chen, C.X.; Xu, L.; Jonas, J.B. Retinal nerve fibre layer thickness measured by Spectralis spectral-domain optical coherence tomography: The Beijing Eye Study. Acta Ophthalmol. 2014, 92, e35-e41. [CrossRef]

18. Kausar, A.; Akhtar, N.; Afzal, F.; Ali, K. Effect of refractive errors/axial length on peripapillary retinal nerve fibre layer thickness (RNFL) measured by Topcon SD-OCT. J. Pak. Med. Assoc. 2018, 68, 1054-1059.

19. Yanni, S.E.; Wang, J.; Cheng, C.S.; Locke, K.I.; Wen, Y.; Birch, D.G.; Birch, E.E. Normative reference ranges for the retinal nerve fiber layer, macula, and retinal layer thicknesses in children. Am. J. Ophthalmol. 2013, 155, 354-360.e1. [CrossRef]

20. Salchow, D.J.; Oleynikov, Y.S.; Chiang, M.F.; Kennedy-Salchow, S.E.; Langton, K.; Tsai, J.C.; Al-Aswad, L.A. Retinal nerve fiber layer thickness in normal children measured with optical coherence tomography. Ophthalmology 2006, 113, 786-791. [CrossRef]

21. Tsai, D.C.; Huang, N.; Hwu, J.J.; Jueng, R.N.; Chou, P. Estimating retinal nerve fiber layer thickness in normal schoolchildren with spectral-domain optical coherence tomography. Jpn. J. Ophthalmol. 2012, 56, 362-370. [CrossRef]

22. Banc, A.; Ungureanu, M.I. Normative data for optical coherence tomography in children: A systematic review. Eye 2021, 35, 714-738. [CrossRef]

23. Chen, L.; Huang, J.; Zou, H.; Xue, W.; Ma, Y.; He, X.; Lu, L.; Zhu, J. Retinal nerve fiber layer thickness in normal Chinese students aged 6 to 17 years. Investig. Ophthalmol. Vis. Sci. 2013, 54, 7990-7997. [CrossRef]

24. Zhu, B.D.; Li, S.M.; Li, H.; Liu, L.R.; Wang, Y.; Yang, Z.; Li, S.Y.; Kang, M.T.; Fu, J.; Qi, Y.H.; et al. Retinal nerve fiber layer thickness in a population of 12-year-old children in central China measured by iVue-100 spectral-domain optical coherence tomography: The Anyang Childhood Eye Study. Investig. Ophthalmol. Vis. Sci. 2013, 54, 8104-8111. [CrossRef]

25. Bendschneider, D.; Tornow, R.P.; Horn, F.K.; Laemmer, R.; Roessler, C.W.; Juenemann, A.G.; Kruse, F.E.; Mardin, C.Y. Retinal nerve fiber layer thickness in normals measured by spectral domain OCT. J. Glaucoma 2010, 19, 475-482. [CrossRef]

26. Kang, S.H.; Hong, S.W.; Im, S.K.; Lee, S.H.; Ahn, M.D. Effect of myopia on the thickness of the retinal nerve fiber layer measured by Cirrus HD optical coherence tomography. Investig. Ophthalmol. Vis. Sci. 2010, 51, 4075-4083. [CrossRef] 
27. Zhang, X.; Li, E.Y.; Leung, C.K.; Musch, D.C.; Tang, X.; Zheng, C.; He, M.; Chang, D.F.; Lam, D.S. Prevalence of visual impairment and outcomes of cataract surgery in Chaonan, South China. PLoS ONE 2017, 12, e0180769. [CrossRef]

28. Jonas, J.B.; Muller-Bergh, J.A.; Schlotzer-Schrehardt, U.M.; Naumann, G.O. Histomorphometry of the human optic nerve. Investig. Ophthalmol. Vis. Sci. 1990, 31, 736-744.

29. Jammal, A.A.; Thompson, A.C.; Mariottoni, E.B.; Estrela, T.; Shigueoka, L.S.; Berchuck, S.I.; Medeiros, F.A. Impact of Intraocular Pressure Control on Rates of Retinal Nerve Fiber Layer Loss in a Large Clinical Population. Ophthalmology 2021, $128,48-57$. [CrossRef]

30. Tu, S.; Li, K.; Ding, X.; Hu, D.; Li, K.; Ge, J. Relationship between intraocular pressure and retinal nerve fibre thickness loss in a monkey model of chronic ocular hypertension. Eye 2019, 33, 1833-1841. [CrossRef]

31. Xu, L.; Zhou, J.Q.; Wang, S.; Wang, Y.X.; You, Q.S.; Yang, H.; Zhang, Y.Q.; Wu, M.Y.; Lu, Y.F.; Fan, Y.Y.; et al. Localized retinal nerve fiber layer defects and arterial hypertension. Am. J. Hypertens. 2013, 26, 511-517. [CrossRef]

32. Baran, R.T.; Baran, S.O.; Toraman, N.F.; Filiz, S.; Demirbilek, H. Evaluation of intraocular pressure and retinal nerve fiber layer, retinal ganglion cell, central macular thickness, and choroidal thickness using optical coherence tomography in obese children and healthy controls. Niger. J. Clin. Pract. 2019, 22, 539-545. [CrossRef] [PubMed]

33. Ozen, B.; Ozturk, H.; Catli, G.; Dundar, B. An Assessment of Retinal Nerve Fiber Layer Thickness in Non-Diabetic Obese Children and Adolescents. J. Clin. Res. Pediatr. Endocrinol. 2018, 10, 13-18. [CrossRef] [PubMed]

34. Gangwani, R.A.; Lee, J.W.Y.; Mo, H.Y.; Sum, R.; Kwong, A.S.K.; Wang, J.H.L.; Tsui, W.W.S.; Chan, J.C.H.; Lai, J.S.M. The Correlation of Retinal Nerve Fiber Layer Thickness with Blood Pressure in a Chinese Hypertensive Population. Medicine 2015, 94 , e947. [CrossRef] [PubMed]

35. Lu, T.L.; Wu, J.F.; Ye, X.; Hu, Y.Y.; Wu, H.; Sun, W.; Guo, D.D.; Wang, X.R.; Bi, H.S.; Jonas, J.B. Axial Length and Associated Factors in Children: The Shandong Children Eye Study. Ophthalmologica 2016, 235, 78-86. [CrossRef]

36. Li, D.; Rauscher, F.G.; Choi, E.Y.; Wang, M.; Baniasadi, N.; Wirkner, K.; Kirsten, T.; Thiery, J.; Engel, C.; Loeffler, M.; et al. Sex-Specific Differences in Circumpapillary Retinal Nerve Fiber Layer Thickness. Ophthalmology 2020, 127, 357-368. [CrossRef] 